Volume $5 \quad 1992$
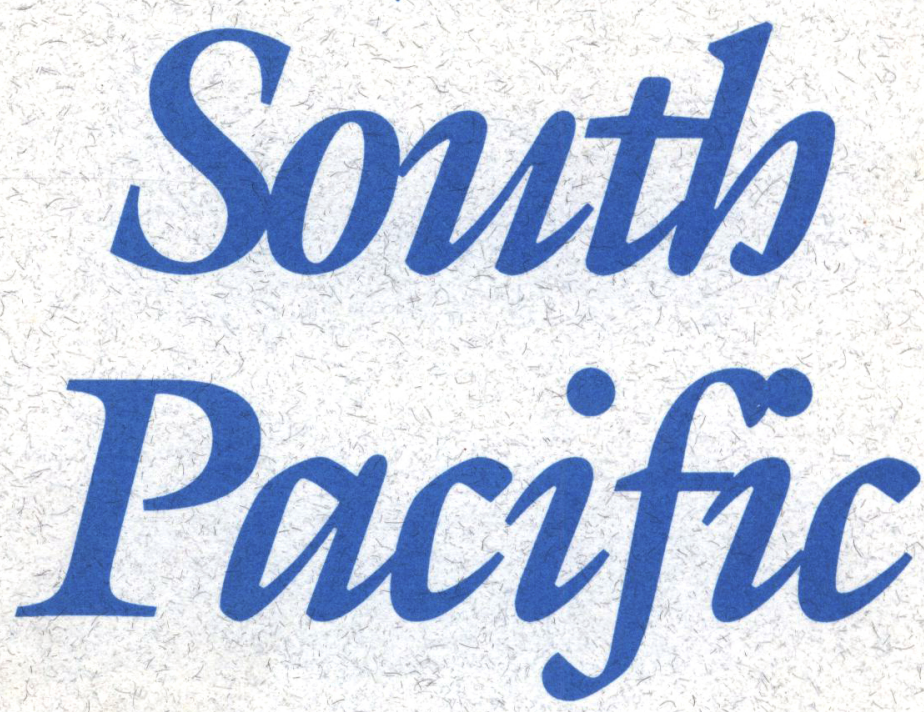

\title{
Journal of Psychology
}

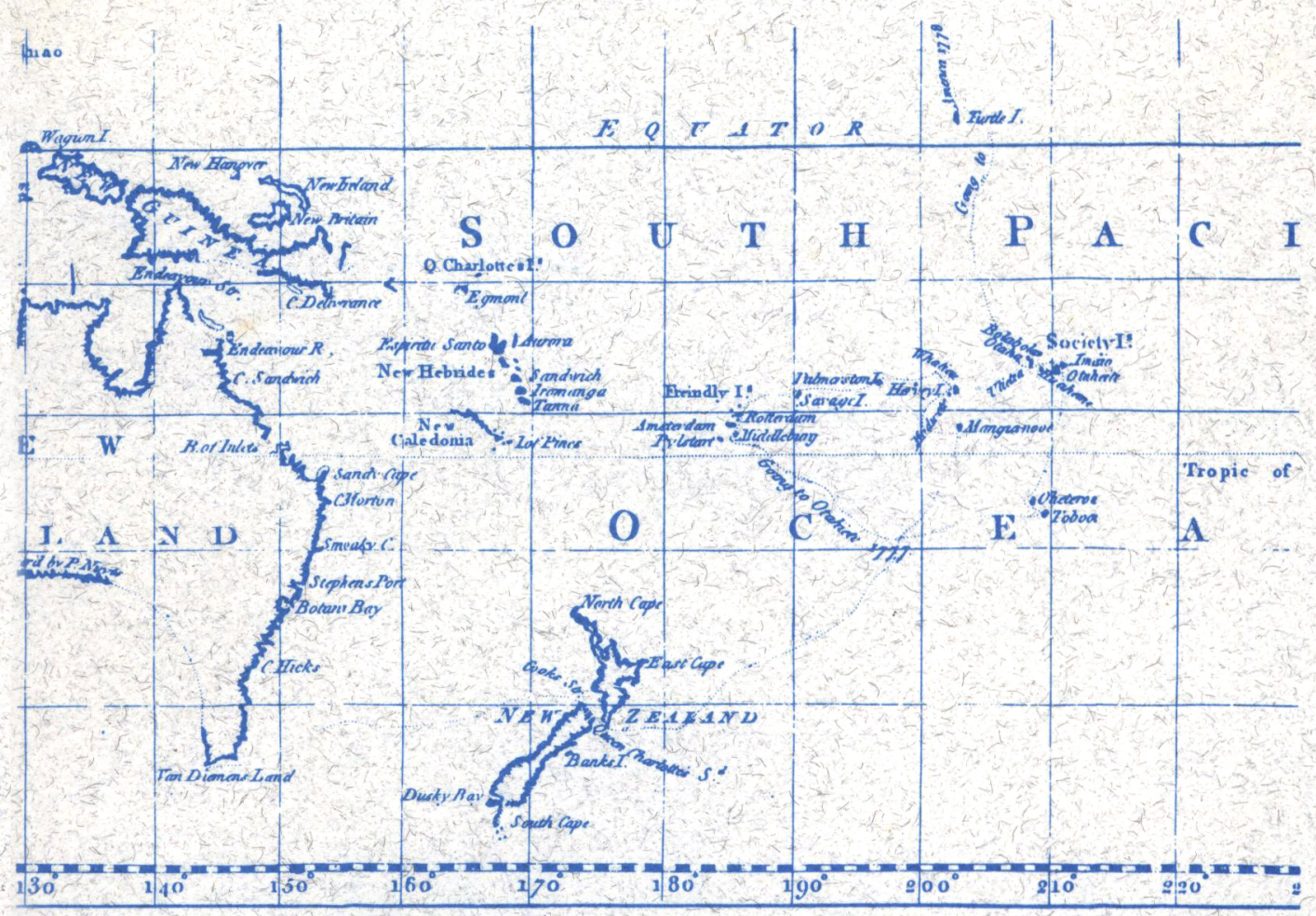




\section{SOUTH PACIFIC}

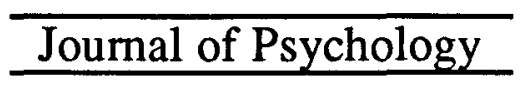

VOLUME 5

1992

Editor

Murray J. Dyck

University of Central Queensland

Associate Editors

Graham R. Davidson

University of Central Queensland

David Lea

University of Papua New Guinea

Jeannette P. Maas

University of the South Pacific

Don Munro

University of Newcastle

Ross St George

Massey University

Ron Taft

Melbourne

David R. Thomas

University of Waikato

\section{TABLE OF CONTENTS}

\section{ARTICLES}

Toward an Applied Aboriginal Psychology .......................1

Graham R. Davidson

The Incidence of Homesickness in a Third World University..........21 Albert Mellam

A Survey of Self-Reported Problems Among Tertiary Students.......24

Albert Mellam and Terence Kuaru

Predicting the Peacetime Performance of Military

Officers: Officer Selection in the Papua New Guinea

Defence Force.

Louis Bau and Murray Dyck

Learned Helplessness and Aboriginal Intra-cultural

Crime and Violence .............................................38

Barbara Miller

Mental States as Social Discourse.

Warwick Mules

See inside back cover for publication policy, instructions to authors, and information concerning subscriptions. 